\title{
REFLEXÕES SOBRE BIOGERONTOLOGIA COMO UMA CIÊNCIA GENERALISTA, INTEGRATIVA E INTERATIVA
}

\author{
Ivana Beatrice Mânica Da Cruz \\ Carla Helena Augustin Schwanke
}

\section{Resumo}

O texto compila conceitos e informações relacionados com um ramo recente da biologia do desenvolvimento, denominado biogerontologia ou biologia do envelhecimento. Reflexões sobre o conjunto de conhecimentos relatado, associado a aspectos sociais, antropológicos e psicológicos são feitas. A síntese do texto, preconiza a importância de rompermos com a ignorância a respeito das modificações associadas ao envelhecimento humano como uma forma de manejar de modo adequado este período da vida auxiliando, deste modo, na diminuição da marginalização e isolamento do idoso que acontece na nossa sociedade.

\section{Abstract}

The text resumes concepts and informations related to a recent branch of the biology of development, named biogerontology or biology of aging. Reflections about the knowledge, associated to social, antropological and psicological aspects are made. The synthesis of the text precognize the importance of breaking the ignorance about the modifications related to human aging as a way to handle in a good way this time of life, and, in this way help to lower the marginalization and isolation of the elder that happens in our society.

'Bióloga, Geneticista, Professora Adjunta, Faculdade de Biociências e Instituto de Geriatria e Gerontologia - Centro Colaborador para a Prevenção de Patologias e Doenças Crônico-Degenerativas Associadas à Idade, Pontifícia Universidade Católica do Rio Grande do Sul.

${ }^{2}$ Geriatra, Mestre em Clínica Médica, Doutoranda do Programa de Pós-Graduação em Gerontologia Biomédica, Pontifícia Universidade Católica do Rio Grande do Sul.

Estud. interdiscip. envelhec., Porto Alegre, v.3, p.7-36, 2001. 


\section{Introdução}

O que é a biogerontologia? Reflexões iniciais sobre este ramo da biologia do desenvolvimento

A biogerontologia, ou biologia do envelhecimento, é um ramo científico recente da biologia do desenvolvimento que se dedica ao estudo dos processos que envolvem as modificações biológicas nos seres vivos, que ocorrem após o período reprodutivo, influenciadas pela interação de fatores genético-ambientais (Bellamy, 1995).

A biogerontologia nasceu e começou a ganhar consistência a partir do final do século XIX, sedimentando-se ao longo do século XX. Entretanto, ela tem sido um ramo praticamente desconhecido e ignorado do grande público, ainda que muita atenção tenha sido dada aos aspectos biológicos relacionados com o envelhecimento humano, incluindo as questões clínicas, sociais, econômicas e psicológicas.

Porém, os interesses começaram a mudar, em parte devido às mudanças demográficas que estão acontecendo no mundo, levando ao aumento na proporção de idosos na população e, em parte, por estarmos longe do entendimento dos processos biológicos básicos que incidem sobre a determinação do envelhecimento. Assim, com o aumento das inovações tecnológicas e científicas que incluíram, principalmente, avanços na área genética e na biologia molecular associado à necessidade de aprendermos mais sobre como os seres vivos e como as pessoas envelhecem, a biogerontologia é uma área que tende a crescer no meio científico e a ocupar um lugar de destaque nas próximas décadas.

Uma vez que a biogerontologia é uma área do conhecimento que ficou fragmentada em outras áreas científicas que estudavam algumas questões do processo de envelhecimento, o conjunto de informações sobre tal tema apresenta-se diluído e, não raro, mesclado a mitos e verdades genéricas. Esta dissipação de conhecimento sem a construção de uma identidade científica pode também ter contribuído para a manutenção da idéia de que velhice seria sinônimo de doença e improdutividade e, portanto, o velho seria um produto potencialmente "descartável". Este fato vai ao encontro da leitura social do papel do idoso nas sociedades ocidentais feita por diversos autores. 
Dentro do processo de ruptura da marginalização do idoso que proporcione uma transição concreta de um paradigma de exclusão para um de inclusão, precisamos desenvolver estratégias que incluam a disseminação do conhecimento sobre as mudanças biológicas associadas ao processo do envelhecimento.

Apesar da biogerontologia ter permanecido fora da "vista da sociedade" por um tempo excessivamente longo, dado o baixo interesse do coletivo social sobre o tema, o processo do envelhecimento e de longevidade foi um objeto de pesquisa tão ou mais perseguido, quanto foi ao longo deste século, a busca da identificação e entendimento da molécula que determinava as características genéticas dos organismos: o DNA.

Sendo um "tema perseguido", por que ele ficou na obscuridade ao longo do século XX? Pensamos que, devido a vários motivos. Destes, podemos destacar dois: o primeiro diz respeito ao próprio comportamento das pessoas em relação ao envelhecimento, que inclui o medo de debater e saber mais sobre o último estágio do desenvolvimento humano (o estágio que precede à morte!). Então, acreditamos que a própria produção do conhecimento científico sobre o tema envelhecimento, tenha permanecido na obscuridade, pelo medo que o tema potencialmente desperta em muitas pessoas, incluindo cientistas e pessoas que trabalham com a gerontologia. $\mathrm{O}$ segundo motivo, centra-se na questão de que investigar e produzir conhecimento sobre o envelhecimento significa trabalhar com visões multifacetadas e diversificadas deste processo, uma vez que se trata de um processo eminentemente multifatorial. Ou seja, a ciência não detectou, ao longo da sua história, nenhuma causa direta (um único gene ou um único fator ambiental) do envelhecimento e da morte. Então, hoje admitimos que este processo é causado e desencadeado por diversos fatores heterogêneos que associam fatores genéticos com ambientais, incluindo como variáveis ambientais o entorno sócio-econômico-cultural onde um dado indivíduo ou uma dada população vivem.

Deste modo, as investigações biológicas sobre processos multifacetados acabaram ficando em segundo plano durante o século do "iluminismo científico da civilização humana" como é considerado o século XX por muitos cientistas. Isto porque, apesar do século XX ser de grande produção de conhecimento 
científico e tecnológico, ele foi marcado pelas "especializações". Assim, até a década de 70, pouca ou nenhuma intersecção entre diversas abordagens biológicas e sociais foram feitas para explicar fenômenos biológicos complexos como é o caso do envelhecimento. Quem o fez, o fez nas sombras, e no reduto de pequenos grupos científicos. Quem o fez, o fez contra o "modismo das superespecialidades e da visão reducionista", que estava até recentemente em voga nas ciências ditas "naturais" que incluem as ciências biomédicas. Não queremos dizer com isto, que o "reducionismo biológico não tenha sido de grande importância para os avanços científicos vividos ao longo do século XX. Como comenta John Bonner, no seu livro A Evolução da Cultura nos Animais, “... as ciências biológicas e biomédicas têm passado por um período reducionista extraordinariamente bem sucedido." (Bonner, 1996).

$\mathrm{Na}$ biologia, ainda que seja difícil apurar quando este processo reducionista começou, alguns trabalhos marcantes principalmente na genética, podem ser destacados. Entre estes o de Mendel (que determinou o padrão básico da hereditariedade genética), Darwin e Wallace (que elaboraram a teoria evolutiva das espécies), Watson e Crick (que propuseram o modelo da estrutura do material genético, o DNA), e Fisher, Haldane, e Sewal Wright que imprimiram a era "neodarwinista" às ciências biológicas, através da elaboração de modelos matemáticos que explicavam a evolução das espécies pela ação de quatro fatores evolutivos: seleção natural, mutação, migração e o acaso (deriva genética), entre outros, e que culminou na elaboração da chamada "nova teoria sintética da evolução".

É claro que os processos do envelhecimento e longevidade também foram exaustivamente investigados ao longo destes últimos cem anos, incorporando os avanços teóricos e experimentais, que o reducionismo biológico produziu ao longo do caminho.

Provavelmente, foi esta "pobreza de interatividade" que permitiu a proliferação de um amontoado de teorias sobre o envelhecimento que, no fundo, praticamente nos dizem a mesma coisa: existem elementos intrísincos e extrínsicos que desencadeiam o processo de envelhecimento, sejam estes condicionados geneticamente ou ambientalmente, ou através da interação dos mesmos. Agora, não existem ainda respostas robustas para perguntas de como 
este processo realmente ocorre. Para tanto, ainda é necessário que a ciência biogerontológica percorra muitos caminhos, no sentido de elucidarmos o conjunto de modificações que levam ao envelhecimento e a morte do indivíduo.

Como existe uma multiplicidade de evidências relacionadas com o envelhecimento, cada teoria sugere ser um dos seus componentes o ponto de origem do processo de modificações associadas à idade, que acabam levando à morte do indivíduo, e se volta à tentativa de provar sua sugestão ou hipótese.

A seguir é apresentada uma síntese das principais teorias sobre o envelhecimento, destacando-se os pressupostos e situação atual das mesmas (modificado a partir de Hayflick, 1996).

\section{Teoria da "substância vital" - teoria do ritmo da vida}

Idéia principal: os organismos começam sua vida com uma quantidade limitada de alguma substância vital, que perdem ao longo da vida. Uma visão moderna propõe que nós nascemos com uma capacidade limitada ou um número específico de batimentos cardíacos ou respirações.

Evidências: nenhuma.

Teoria da mutação genética

Idéia principal: ocorrência e aumento de mutações nos genes acabariam causando o envelhecimento, porque os genes mutados sofreriam alterações que implicariam em mal funcionamento e morte das células corporais

Evidências: não existem indícios experimentais que a comprove.

Teoria da exaustão reprodutiva

Idéia principal: esta teoria preconiza que o período reprodutivo seria precursor do envelhecimento. De todas as teorias, particularmente acreditamos que esta seja uma das que contém maiores "verdades" sobre o processo de envelhecimento. Entretanto, acreditamos que algumas considerações ecológicas e evolutivas poderiam incrementá-la e, quem sabe, torná-la a base da teoria 
sintética do envelhecimento.

Evidências: há indícios convincentes e exemplos na natureza da relação "reprodução-longevidade" são encontrados com relativa facilidade. Por exemplo, o caso do salmão que se desenvolve no mar e, quando amadurece, migra para a foz do rio para se reproduzir e desovar. Neste processo migratório, o desgaste energético é intenso, além do que a espécie tem que gerenciar mudanças no equilíbrio corporal devido as modificações na concentração dos sais (concentração iônica) existentes entre a água salgada e a do rio. Um processo de degeneração do sistema digestivo também é bem marcante. No final do período reprodutivo, o salmão totalmente desgastado e sem condições de se alimentar visto que o seu tubo digestivo sofreu um profundo processo de atrofia, morre. Evidências em outras espécies como as de alguns moluscos, flores e plantas anuais, também apoiam esta teoria.

Teoria neuroendócrina

Idéia principal: esta teoria preconiza que a falência progressiva de células com função integrativa como é o caso do sistema nervoso e do sistema hormonal (endócrino) levaria ao envelhecimento e ao colapso do sistema corporal. Evidências: apesar do sistema neuroendócrino exercer um efeito dramático sobre todo o organismo, não há indícios diretos de que seja a origem de todas as mudanças associadas à idade.

Teoria do desgaste (teoria do soma descartável)

Idéia principal: é uma das primeiras teorias do envelhecimento, tendo sido proposta por August Weismann em 1882. A morte ocorreria porque um tecido desgastado não pode se renovar eternamente. O corpo desgastaria com o passar do tempo, levando ao envelhecimento e morte.

Evidências: existem evidências de desgate nos organismos. 
Se o desgaste é uma causa fundamental das mudanças associadas a idade, então, segundo pesquisadores contemporâneos como Miquel, tais desgastes aconteceriam em nível molecular. Moléculas importantes ficariam sujeitas a danos ao longo do tempo e organelas também. Este é o caso do DNA e das mitocôndrias. Apesar de ser teoricamente factível, existem dificuldades em comprovar realmente tal teoria.

Teoria do acúmulo de resíduos

Idéia principal: esta teoria sugere que ocorreria acúmulo de resíduos e toxinas no interior das células, produtos do próprio metabolismo, que poderiam prejudicar a função celular normal e matar lentamente a célula.

Evidências: existem alguns indícios de que ocorrem acúmulos de resíduos no interior das células. Um destes resíduos mais estudados é a lipofucscina. Esta substância é um pigmento marrom que se acumula em pequenos grânulos no interior das células à medida que o corpo envelhece. Entretanto, a maioria dos biogerontólogos não acredita que apenas este tipo de situação biológica levaria as mudanças associadas ao envelhecimento.

Teoria das ligações cruzadas

Idéia principal: tal teoria postula que, com o passar do tempo, ocorre um aumento no número de ligações cruzadas entre algumas proteínas das células, inclusive o colágeno. Estas ligações cruzadas impedem os processos metabólicos normais através da obstrução da passagem de nutrientes e resíduos da parte interna para a externa das células e viceversa. Assim, acumulariam erros nestas moléculas levando à disfunção e morte celular e do corpo. Para tanto, estas ligações ocorreriam também no DNA.

Evidências: apesar de haverem indícios científicos de que ao longo do envelhecimento ocorrem ligações cruzadas 
entre proteínas, não existem evidências consistentes de que tais ligações ocorreriam no DNA e seriam responsáveis pelo envelhecimento em si.

Teoria dos radicais livres

Idéia principal: esta é uma das teorias que está mais na moda no presente momento. Ela baseia-se no fato de que todos os animais aeróbicos necessitam de oxigênio para produzir energia. Este processo denomina-se respiração celular, e ocorre na organela celular denominada mitocôndria. Entretanto, cerca de $2 \%$ do oxigênio que entra para dentro da célula não é ocupado no processo de respiração, e acaba formando moléculas chamadas de ELEMENTOS ATIVOS DE OXIGÊNIO (EAOs) ou radicais livres. Tais moléculas são altamente reativas, ligando-se nas membranas celulares e no DNA. Tais ligações causam danos terríveis. Somente para ilustrar o significado do dano oxidativo, a ferrugem em uma barra de ferro nada mais é do que o produto de uma reação entre o oxigênio presente na atmosfera e do ferro que compõe tal barra. Se o oxigênio consegue esbororar materiais do tipo barras de ferro, imagine o que ele é capaz de fazer a uma membrana composta basicamente por gorduras (lipídios) e proteínas! Para nos protegermos contra os radicias livres, existem uma bateria de enzimas celulares chamadas: enzimas anti-oxidantes. Estas enzimas são sintetizadas pela própria célula, a partir de genes presentes no DNA do organismo. Basicamente, estas enzimas impedem ou tentam impedir a ação dos radicais livres. Além destas enzimas, o nosso organismo é ajudado por substâncias encontradas nos alimentos (como frutas e vegetais $=$ compostos anti-oxidantes, principalmente vitamina $\mathrm{C}$ e E). Tais substâncias, auxiliariam a proteção celular contra a ação das EAOS. A idéia de que os radicais 
livres conduziram ao processo do envelhecimento, baseiase em evidências que mostram que os radicais livres produzem: pigmentos celulares, ligações cruzadas e danos no DNA com o passar da idade.

Evidências: apesar de uma série de evidências que mostram a relação dos radicais livres e modificações prejudiciais das células associadas, nenhum experimento até o presente momento, mostrou que os anti-oxidantes ou um sistema anti-oxidante mais ativo, aumentariam o tempo de vida de um organismo. Entretanto, é uma teoria que ainda está sendo testada, possui muitos adeptos e que seguramente mostra que os radicais livres contribuem em algum nível no processo de envelhecimento.

\section{Teoria do Sistema Imunológico}

Idéia principal: uma das teorias baseadas no envelhecimento morfo-fisiológico seria a da perda funcional do sistema imune. Este declínio levaria ao envelhecimento e morte corporal. Tal teoria baseia-se em duas grandes descobertas feitas ao longo destas últimas décadas que estão relacionadas com o sistema imune e envelhecimento: 1) com a idade, a capacidade do sistema imune produzir anticorpos em número e tipo adequados diminui (suscetibilidade a doenças); 2) com a idade, o sistema imune pode produzir incorretamente anticorpos contra proteínas normais do nosso corpo (levando a doenças auto-imunes).

Evidências: apesar de ser evidenciado tais mudanças, não se observou diretamente que as mesmas poderiam ser as desencadeantes principais do processo de envelhecimento.

Teoria dos erros e reparos (envelhecimento pleiotrópico)

Idéia principal: tal teoria propõe que existiram genes cujos produtos que seriam benéficos no início da vida (principalmente ao longo do desenvolvimento inicial dos 


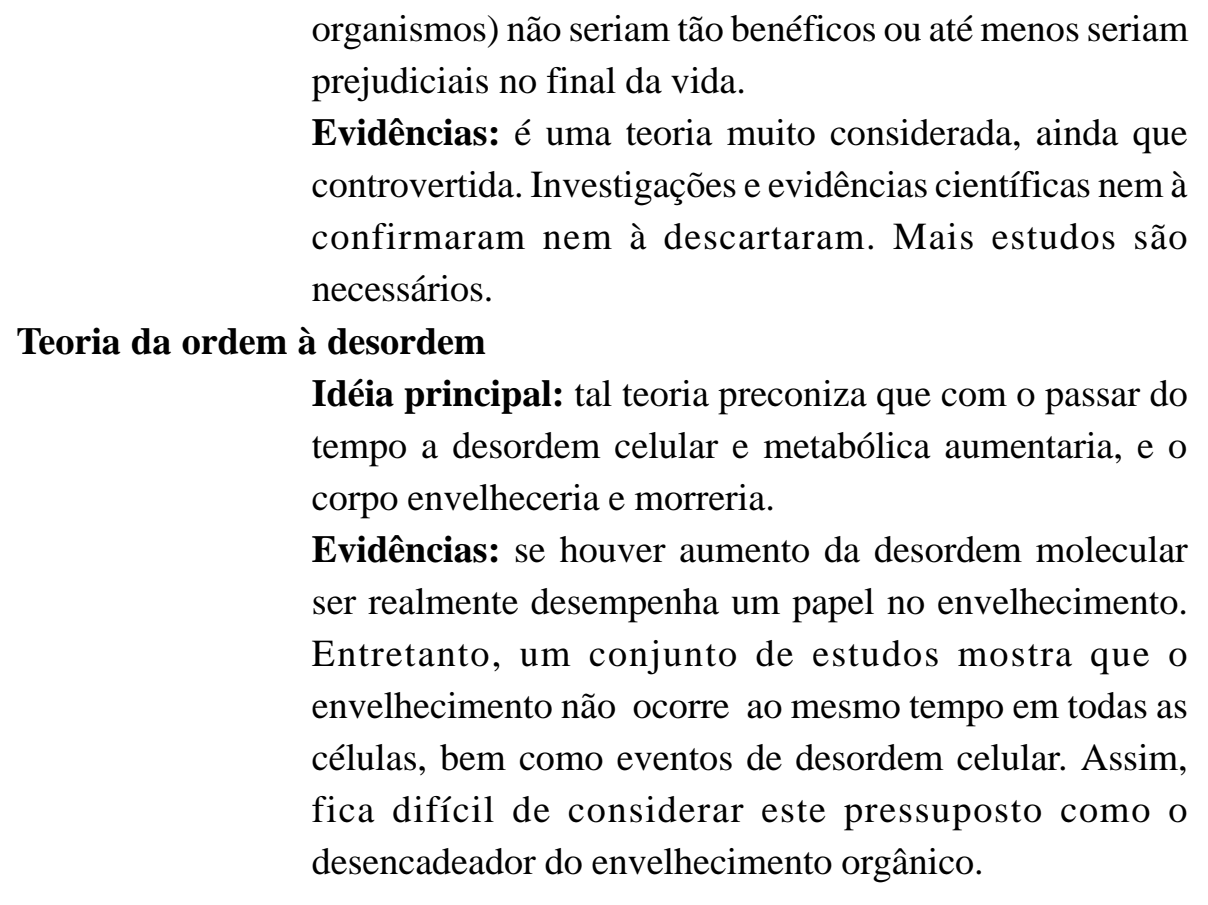

Felizmente, o final do "século das luzes científicas", nos brindou com o melhor de todos os presentes: a volta a interatividade entre as diversas áreas e abordagens científicas! Ano a ano, principalmente nestas duas últimas décadas, os que se arvoravam fora dos seus limitados campos do conhecimento puderam se expor mais e trabalhar mais nas zonas marginais entre duas ou mais ciências, entre duas ou mais especialidades, sem serem imediatamente marginalizados dentro da sua especialidade. Ou seja, a "cristalização das áreas científicas imposta pelo movimento reducionista". É claro que, ainda para uma grande maioria dos pesquisadores, é um pecado quase mortal sair do seu círculo de tema de investigação, e eles olham os que o fazem, com desconfiança e restrição. Mas, a interdisciplinariedade e a multidisciplinariedade, já é hoje, um caminho sem volta, por ser o único caminho a ser trilhado para explicarmos eventos biológicos complexos.

A alta especialização nas diversas áreas científicas, fez com que houvesse um trabalho paralelo, que gerou a partir de um modo de trabalho árduo e 
aprofundado uma avalanche de informações biológicas, que hoje já são o suficiente para começarmos a desenvolver trabalhos multifacetados, que permitam repensar e reanalisar aspectos complexos, não lineares e com padrões em rede, como é o caso do surgimento da vida no planeta e do envelhecimento orgânico.

Nestes termos, acreditamos que estamos nos preparando para o desenvolvimento de uma teoria sintética do envelhecimento que oriente-se desde aspectos moleculares relacionados ao processo até aspectos ecológicoevolutivos relacionados com os organismos vivos, e de aspectos sociológicos e antropológicos mais diretamente relacionados com o próprio homem.

Já começa a existir esta necessidade de agrupamento e de síntese sobre as causas do envelhecimento e da longevidade. George Martin, professor da Universidade de Washington, recentemente publicou um capítulo chamado Genes that modulate longevity and senescence, editado por Jean-Marie Robine e Bernard Forette no livro The Paradoxes of Longevity, onde agrupa todos os pesquisadores em biogerontologia que preocupam-se em estudar as causas que levam ao envelhecimento em duas categorias: os "simplificacionistas" e os “complicacionistas" (Martin, 1999).

Os simplificacionistas acreditam que o envelhecimento ocorre porque não existe uma pressão de seleção nas espécies e nos homens, que aconteça nesta fase. O que isto significa? Por exemplo, se existe uma determinada pessoa idosa que possui uma característica genética diferenciada que à leve a ser resistente a uma determinada doença que só aconteça após o seu período reprodutivo, como ela não pode mais ter filhos, ela acaba não transmitindo esta característica genética para as próximas gerações. Assim, mesmo que ela sobreviva em relação aos outros idosos que não possuam tal característica, ela passará esta informação genética à prole por acaso, e não porque foi positivamente selecionada. O caso contrário também seria verdadeiro. Se a pessoa for mais suscetível a uma doença que ocorra após o período reprodutivo, influenciada por uma dada característica genética que a pessoa herdou de seus pais, e como, apesar disto, conseguiu ter filhos, tais características ruins acumular-se-iam no genoma da pessoa e de seus filhos. O envelhecimento, então, aconteceria porque ao longo da nossa evolução teríamos muitas variantes 
genéticas "ruins" que só agiriam no nosso envelhecimento, ou variantes genéticas que seriam "bons" no início do nosso desenvolvimento e "ruins" no final da nossa vida. A síntese desta visão seria a de que, o que é velho, potencialmente é descartável.

Já os complicacionistas, nos quais o autor se inclui, pensam que o envelhecimento ocorre por que é uma fase do desenvolvimento controlada pela ação de genes que poderiam ter suas atividades moduladas, retardando ou acelerando o processo de envelhecimento pela ação de variáveis ambientais. No homem, este processo também ocorreria, sendo as condições biopsicosociais muito importantes na determinação do processo da velhice.

Apesar desta tentativa de síntese, muitos pesquisadores não conseguem se incluir totalmente em nenhum destes dois grupos. Muitos acreditam, como é o nosso caso, que o envelhecimento e a morte são parte natural da vida e que devemos aceitar este fato. Isto porque, a harmonia do planeta e da própria ontogenia humana, passa pelo reciclar das gerações. No caso, se nós fossemos potencialmente imortais, teríamos que abandonar o prazer (e a estratégia biológica) de termos filhos e netos, caso contrário, esgotaríamos rapidamente aos recursos naturais, o que levaria à morte da nossa própria espécie e das demais espécies vivas. Assim, acreditamos ser justa a existência de mecanismos que acabem determinando nosso envelhecimento e nossa própria morte. Mecanismos estes, que iniciam com um processo genético que leve ao envelhecimento e morte, e que são potencializados pelo ambiente.

Deste modo, muitos pesquisadores acreditam que existe, após o período reprodutivo, uma cascata de eventos biológicos organizados que levam ao acúmulo de modificações biológicas com o objetivo de que o organismo morra no final. Entretanto, acreditamos também que tal processo não signifique que tenhamos que sofrer o acúmulo de morbidades e co-morbidades que podem estar associadas à velhice. Evidências científicas já apontam para a possibilidade de construção de estratégias que podem retardar ou diminuir a velocidade do aparecimento das modificações associadas ao envelhecimento. Ou seja, o conjunto de conhecimentos produzidos sobre o tema nos direciona para a idéia de que podemos modular a velhice de forma a tornar nossos últimos anos uma fase a ser vivida em toda a sua plenitude, respeitando suas limitações, assim 
como respeitamos as limitações de outras fases biológicas que vivemos previamente: a infância, a adolescência e a fase adulta.

2 Biogerontologia como uma Ciência Generalista, Integrativa e Interativa

Após as considerações iniciais sobre a biogerontologia, cabe destacar os motivos pelos quais podemos classificá-la como uma ciência generalista, integrativa e interativa.

A biogerontologia é uma ciência generalista, uma vez que ela foge do padrão de produção de conhecimento científico por especialização e centrado em uma única abordagem, seja esta, fisiológica, clínica, genética, sociológica, etc. Portanto, ela emerge como uma ciência que toma para si informações de diversas abordagens, e generaliza tais informações num "todo". Para fazer isto, necessariamente, tal ciência deve ser integrativa, pois para investigar o processo de envelhecimento como um "todo" ela necessitará unir conhecimentos sobre o processo de envelhecimento que foram produzidos nas diversas áreas científicas tanto biológicas quanto humanas. Para integrar, ela necessita interagir. Assim a biogerontologia é uma ciência cujo campo de estudo é altamente interativo, pois, a visão do todo precisa ser construída entre pesquisadores que olham desde os aspectos moleculares até os aspectos sociais que influenciam a dinâmica do processo de envelhecimento e da gênese das incapacidades e doenças associadas.

Dada esta sua natureza, generalista, integrativa e interativa, a biogerontologia do futuro conta com enormes desafios, que passam necessariamente pela construção de uma prática de pesquisa fortemente interdisciplinar, em que vários profissionais olham para o processo de envelhecimento, cada um através da sua especialidade, e estabelecem pontes de interação (que aqui poderíamos denominar de "sinapses científicas interdisciplinares" fazendo uma analogia com a plasticidade do nosso sistema nervoso quando constrói novas experiências de vida) que orientam a construção do nosso entendimento sobre o "envelhecer".

Baseados nestas considerações, a seguir reveremos as três questões principais que são tema de investigação da biogerontologia e que estão, de modo direto ou indireto, associadas à geriatria e à gerontologia social.

Estud. interdiscip. envelhec., Porto Alegre, v.3, p.7-36, 2001. 


\section{As Três Questões Básicas da Biogerontologia Moderna}

Existem três questões básicas na biogerontologia, segundo Leonard Hayflick que é um biólogo celular que dedicou sua vida a estudar o envelhecimento citológico (Hayflick, 1996). A primeira, é aquela que sintetiza investigações sobre o período que se espera que um animal ou que o homem viva, considerando as melhores circunstâncias ambientais. Sua hipótese geral baseia-se na questão: por que vivemos tanto?

A segunda, é aquela que sintetiza investigações sobre as modificações morfo-fisiológicas associadas à idade. Sua hipótese geral baseia-se na questão: por que nós envelhecemos?

A terceira, é aquela que sintetiza investigações sobre o processo evolutivo que levou a formação de seres vivos que possuem um tempo de vida limitado, como é o caso da maioria dos seres vivos deste planeta e do próprio homem. Sua hipótese geral baseia-se na questão: por que morremos?

A consideração destas três questões, e a investigação das mesmas, têm levado gerações de pesquisadores a construir o conhecimento que temos hoje sobre o envelhecimento biológico.

\section{0 que Sabemos sobre Biogerontologia: os estudos longitudinais}

Seguramente, dentro das três questões citadas anteriormente, aquela que se pergunta como envelhecemos é a que mais chama a atenção. Saber como envelhecemos, não poderia auxiliar-nos a descobrir mecanismos para não envelhecer? Eis um dos grandes sonhos da humanidade! No momento não temos nenhuma certeza quanto esta perspectiva. Aliás, não temos e não buscamos (os biogerontólogos) esta perspectiva (o anti-envelhecimento). Entretanto, acumulamos informações sobre este processo, obtidas principalmente a partir de estudos em modelos experimentais, e de estudos humanos populacionais longitudinais (Vellas et al., 1997).

Nosso corpo ainda que formado por uma unidade fundamental, a célula, não funciona de modo individualizado. Ou seja, similar a uma orquestra, que guarda particularidades de instrumentos, músicos e a música a ser tocada, é constituído por relações harmônicas. Ao contrário da individualização e de uma máquina como muitos gostam de comparar, o corpo humano representa 
uma extensa rede cooperativada, onde o conjunto de células com estrutura e funções similares, associam-se a outras células formando órgãos e sistemas responsáveis pela manutenção da nossa vida e da nossa relação com o ambiente e com o nosso entorno social.

Esta aparente obviedade é crucial para a gerontologia e para a geriatria. Isto por que, para estabelecermos o que é um estado patológico associado ao envelhecimento, e o que são modificações esperadas neste momento das nossas vidas, foram necessários estudos intrincados.

Estas investigações surgiram da necessidade de compreendermos que tipo de eventos aconteciam na maioria das pessoas ao longo do processo do envelhecimento, e portanto, considerando-se que "normalidade é um conceito de maioria", estes seriam os eventos "potencialmente esperados" de ocorrerem ao longo da nossa velhice, daqueles eventos que poderiam ser considerados "patológicos". Entretanto, existe uma enorme dificuldade em separar estes dois "processos": normalidade e doença! Para fazer isto, só investigando as mudanças biológicas ocorridas ao longo da vida das mesmas pessoas. A partir desta idéia, começaram a florescer os estudos, ditos longitudinais. Um dos mais antigos e mais relevantes, é o estudo chamado Baltimore Longitudinal Study of Aging (BSLA), que iniciou na década de 40 na cidade de Baltimore, Estados Unidos. Tal investigação começou acompanhando a vida de homens brancos, saudáveis. Estas eram as condições fundamentais para a participação no estudo, os chamados "critérios de inclusão". Somente, a partir do final da década de 70, é que foram incluídas as "minorias étnicas" como mulheres e pessoas com étnica diferenticada (africana, asiática. , etc).

Outras investigações deste porte foram também iniciadas, entre as quais destacam-se o estudo da Universidade de Duke, Estados Unidos e de Bonn na Alemanha. Além destes estudos, existem investigações longitudinais observando a evolução de doenças específicas. Como doenças crônicodegenerativas associadas ao envelhecimento têm origem multifatorial, tais estudos serviram também para a identificação de fatores potenciais de risco e de prevenção relacionados com doenças associadas à idade. Para tanto, foram também estruturados estudos populacionais específicos, como os que investigam fenômenos relacionados com o desenvolvimento de doenças cardiovasculares. 
Entre as investigações populacionais importantes implementadas a mais de vinte anos, estão o estudo de Frahmingham, Bogalusa (duas cidades americanas), um estudo multicêntrico e multinacional promovido pela Organização Mundial da Saúde na Europa denominado MONICA (Monitoramento Cardiovascular) que acompanhou a vida de mais de 30 mil voluntários em diversos países europeus, e o CARMEM (Cardiovascular Monitorament) implementado aqui no continente americano que é um projeto irmão do projeto MONICA.

No Brasil, alguns estudos longitudinais tanto com o objetivo de investigar a longevidade quanto para estudar a evolução de doenças em grupos populacionais específicos, começaram a ser implementados a partir da década de 90. Abaixo são descritos de modo resumido os estudos que estão ativos no nosso país, no presente momento:

Estudo Bambuí: investiga a evolução de doenças cardiovasculares em idosos portadores da doença de Chagas, numa cidade metropolitana (Bambuí) de Belo Horizonte;

Estudo Epidoso: investiga principalmente a evolução de doenças neurológicas (demências) em idosos paulistas;

Estudo Veranópolis: investiga fatores genético-ambientais associados ao envelhecimento bem sucedido em idosos com mais de 80 anos de idade. Recentemente, uma nova corte foi feita, sendo constituída de 250 adolescentes entre 10 a 20 anos de idade. A previsão do estudo de seguimento é 20-30 anos;

Estudo Gravataí: também investiga fatores genético-ambientais associados ao envelhecimento e a suscetibilidade à doenças crônicodegenerativas, principalmente cardiovasculares, neoplasias associdas à velhice (principalmente câncer de mama e próstata) e demências. Tais investigações concentram-se em escolares ( 7 a 20 anos de idade) e em idosos socialmente ativos, ou seja, idosos que realizem algum nível de atividade que envolva grupos sociais diferenciados da nucleação familiar. Optou-se pelo estudo deste grupo, por que é o grupo de idosos que potencialmente teria mais facilidade de aderência de comportamentos preventivos à doenças crônico-degenerativas, do que os idosos isolados na família ou ainda mantendo relações famíliatrabalho, ou até mesmo idosos institucionalizados. Dado que a idéia é desenvolvermos investigações que levem a criação de estratégias e instrumentos 
de prevenção, caso os mesmos sejam obtidos, estes podem ser potencialmente utilizados por outros grupos de idosos, sendo necessário apenas estudos complementares que ajustem os métodos e instrumentos aos demais grupos.

Estes dois últimos estudos (Veranópolis e Gravataí) fazem parte de um Programa de Pesquisa denominado genericamente de Programa Genesis de Pesquisa, que foi implementado em 1998 por uma equipe de pesquisadores do Instituto de Geriatria e Gerontologia da Pontifícia Universidade Católica do Rio Grande do Sul. Dado a grande demanda por investigações similares em outras regiões do Rio Grande do Sul e do Brasil, recentemente, um estudo chamado Projeto Grande Longevos começou a ser elaborado e implementado entre pesquisadores baianos e gaúchos. Tal projeto é coordenado pela geriatra Marília Bastos e pelos pesquisadores da PUCRS e tem como objetivo investigar as condições biopsicossociais e de saúde, de pessoas muito idosas (acima de 85 anos) que vivem em diversos municípios brasileiros localizados em nas suas diferentes regiões. A intenção é compararmos os efeitos étnico, geográficos, genético e de estilo de vida, em idosos com o mesmo perfil sócio-economico cultural que vivem espalhados pelo Brasil a fora. Por ser um estudo ambicioso, começamos, é claro, por idosos que vivem em Salvador, em Gravataí e em Porto Alegre.

5 O que Sabemos sobre Biogerontologia: informações sobre o processo

Foi também a partir do conhecimento produzido em estudos longitudinais que aprendemos uma grande lição: sistemas corporais e órgãos, envelhecem em velocidades diferentes, e acumulam modificações diferentes, e muitas vezes disfunções em maior ou menor grau. Assim, existem órgãos ou sistemas que começam a apresentar modificações a partir dos 30 anos de idade e outros que vão acumular diferenças morfológicas e fisiológicas em idades mais avançadas. Além disto, o início do acúmulo destas modificações varia de modo intenso entre etnias e indivíduos. Se compararmos o aparecimento de rugas entre idosos de etnia predominantemente européia (que neste momento chamaremos genericamente de "brancos") e idosos de etnia africana (que chamaremos genericamente de "negros"), observamos que os brancos apresentam uma maior quantidade de rugas que aparecem mais cedo na vida 
cronológica do indivíduo do que nos negros. Um exemplo contrário seria de que, indivíduos negros tem uma influência genética que torna-os menos aptos de ingerir quantidades significativas de sal, e assim, são particularmente suscetíveis ao desenvolvimento da doença hipertensão arterial sistêmica.

Talvez seja esta heterogeneidade tanto do envelhecimento intrínsico (pessoal) quanto do envelhecimento de um determinado grupo étnico, ou um gênero, é que torna tão árdua a tarefa de diferenciarmos o que é normal do que é patológico na velhice. E o que é mais problemático a determinação do que é uma variável de risco para o desenvolvimento de uma doença para todas as pessoas, em todas as idades, e o que é uma variável de risco para subgrupos populacionais específicos, considerando principalmente grupo etário, etnia e gênero é uma tarefa altamente complexa.

Dado que o conjunto das informações a respeito destas mudanças já é razoavelmente grande, uma síntese do que acontece nos nossos órgãos e sistemas ao longo da fase adulta e da velhice é apresentada a seguir, evidenciando modificações morfo-fisiológicas associadas ao envelhecimento humano obtidas a partir de evidências científicas observadas em estudos longitudinais (modificado a partir de Hayflick, 1996 e Arking, 1998).

Composição corporal

Diminuição na quantidade de água intra-celular: 1) nos homens jovens, $61 \%$ do corpo é constituído por água e este percentual baixa para $54 \%$ nos idosos; 2) nas mulheres, este percentual baixa de $54 \%$ para $46 \%$. Diminuição na massa óssea e muscular. A quantidade de gordura permanece estável, mas a localização muda, havendo maior acúmulo nas coxas e abdome.

Metabolismo basal

Diminui com a idade.

Estrutura corporal geral

Diminuição gradual da altura $(0,15 \mathrm{~mm} / \mathrm{ano})$. Peso aumenta entre os 30 e 55 anos, diminuindo após devido à diminuição 
de massa magra. Extremidades corporais tornam-se mais finas e tronco mais grosso. Tórax: diâmetro, circunferência e profundidade aumentam com a idade.

Rosto: nariz e orelhas alongam-se devido ao crescimento contínuo da cartilagem. Crânio: suturas cranianas começam a se fundir a partir dos 70 anos de idade; circunferência e tamanho da cabeça aumentam. Esqueleto: crescimento de alguns ossos (como o da bacia) continua até os 70 anos de idade:

Composição orgânica

A maioria dos órgãos internos diminuem de tamanho possivelmente devido à diminuição da água intra-celular. Alguns órgãos como a próstata, coração, pulmão e pele (dobras) tendem a aumentar.

Mudanças na arcada dentária

Número de cáries aumenta, bem como doença periodontal, podendo levar a perda de dentes. Fluxo de saliva permanece estável, sendo que a "boca seca" não é considerada pela maioria dos autores como um evento normal (pode ser efeito colateral de medicamentos). Estas mudanças podem acarretar alteração na mastigação e contribuir para má nutrição.

Pele e unhas

Ocorre descoloração, rugas e deterioração da pele; há diminuição de elasticidade e flexibilidade. O enrugamento ocorre devido a perda de colágeno, pelo depósito excessivo de elastina e diminuição de gordura na camada abaixo da pele (derme). Tanto a epiderme quanto a derme ficam mais finas com a idade. Assim, aumentam as chances de ocorrer afecções dermatológicas, ressecamento, coceira, calosidades, granulações. As unhas ficam mais opacas e mudam de cor, podendo apresentar sulcos e rachaduras longitudinais. 
Glândulas sudoríparas

Idosos suam menos porque as glândulas sudoríparas atrofiam ou perdem sua função, fazendo com que eles fiquem mais propensos a choques térmicos. Contudo, com a diminuição destas glândulas, o odor exalado diminui (a maioria dos idosos não precisa usar desodorante).

\section{Controle da temperatura}

A camada de gordura da derme diminui, podendo ocorrer hipotermia e desequilíbrio na sensação frio-quente.

Capacidade de cicatrização

É mais lenta porque a taxa de divisão celular é menor.

Cabelo

A densidade, o diâmetro e a força do cabelo diminuem com a idade. $\mathrm{O}$ crescimento do cabelo também diminui, mas em regiões adjacentes como orelhas, narinas e sobrancelhas os pêlos podem sofrer um crescimento contínuo (nas mulheres, após a menopausa, começa haver crescimento de cabelos acima dos lábios, sendo que $40 \%$ das mulheres com idade acima de 55 anos desenvolvem pêlos faciais grosseiros). O embranquecimento dos cabelos é, provavelmente, o sinal mais notável da velhice, sendo considerado o indicador mais confiável do processo de envelhecimento, sobretudo o embranquecimento dos pêlos das sobrancelhas. Entretanto, somente $65 \%$ das pessoas com 60 anos têm cabelos brancos.

Audição

A habilidade de ouvir freqüências mais altas começa a diminuir em torno dos 30 anos. Cerca de 1/3 das pessoas com mais de 65 anos de idade têm problemas de audição. Homens ouvem menos do que as mulheres ao longo do envelhecimento.

Paladar 
Ao contrário do que se pensava anteriormente, parece não haver perdas no número de papilas gustativas e sim mudanças degenerativas. Assim, a capacidade de detectar os 4 paladares (salgado, doce, amargo e ácido) diminui ligeiramente com a idade.

Olfato

Ocorre diminuição gradual da habilidade de detectar e identificar odores. Em um estudo, $45 \%$ dos idosos não passaram no teste de identificar odores (queijo, chocolate, hortelã e sardinhas). No mesmo teste, apenas $4 \%$ dos jovens não conseguiram identificar estes odores.

Visão

Ocorrem alterações no cristalino: esta parte do olho fica mais espessa e mais pesada. A catarata é uma condição associada a mudanças na estrutura proteica do cristalino. Muitos pensam que é uma doença, mas não, seu aparecimento associado a idades avançadas é inevitável.

Sono

As pessoas idosas normalmente passam mais tempo na cama à noite sem tentar dormir ou tentando dormir sem conseguir. Elas passam mais tempo descansando ou cochilando ao longo do dia. Também têm mais insônia e o número de vezes que acordam depois de pegar no sono aumenta (a profundidade do sono diminui com a idade). A frequiência do ronco aumenta: quase $60 \%$ dos homens e $45 \%$ das mulheres idosas roncam habitualmente.

Nutrição

O consumo de alimentos diminui com a idade. Estudos revelaram que a ingestão ideal de energia de 2.700 calorias por dia aos trinta anos cai para 2.100 calorias aos 80 anos. Não se conhece muito ainda sobre as exigências nutricionais dos idosos. Entretanto, investigações recentes sobre o tema mostram que as necessidade de ingestão diária de proteínas 
é maior nas pessoas muito idosas (acima de 80 anos) do que nos adultos. Esta passa de $0.80 \mathrm{~g} / \mathrm{Kg}$ de peso corporal/ dia para $1-1.25 \mathrm{~g} / \mathrm{Kg}$ de peso corporal/dia. Portanto, idosos devem comer mais alimentos ricos em proteínas como leite, ovos e carnes. A desnutrição na pessoa idosa não é rara, principalmente após os 80 anos de idade.

\section{Capacidade para a prática de exercício físico}

A tolerância e desempenho na prática de exercício físico diminuem. A capacidade aeróbica máxima diminui com a idade. Entretanto, pessoas idosas fisicamente ativas têm capacidade aeróbica muito maior do que pessoas da mesma idade ou jovens sedentários. Seus tempos de movimentos e reação são superiores.

Mudanças na personalidade

A personalidade permanece semelhante. A crença de que a pessoa idosa torna-se mal humorada é um mito.

Mudanças na atividade sexual

A atividade e a capacidade sexual tendem a diminuir com a idade. As fantasias sexuais diminuem em freqüência e intensidade. A frequiência relativa da atividade sexual não muda com a idade.

Sistema reprodutor feminino

A maioria das mulheres perde a capacidade de reprodução por volta dos 40 anos. Os óvulos de mulheres mais velhas são defeituosos geneticamente com maior frequiência. Acredita-se que o hipotálamo inicie a menopausa e a seqüência de eventos relacionados. Após a menopausa, ocorre diminuição da massa óssea, do peso e do tamanho do útero, da vagina e de suas secreções. Em $90 \%$ das mulheres, as mamas involuem, tornando-se mais flácidas, sendo que $10 \%$ das mulheres apresentam aumento das mamas por razões ainda desconhecidas. $2 / 3$ de todas as neoplasias mamárias ocorrem em mulheres com mais de 
50 anos de idade.

Sistema Reprodutor Masculino

Modificações são mais graduais do que nas mulheres. O tamanho dos testículos e a contagem de espermatozóide permanecem iguais, mas a proporção de espermatozóides imaturos aumenta com a idade. A próstata tende a aumentar de tamanho, podendo causar constrição do canal urinário (uretra), dificultando a micção. Aumenta a freqüência de hiperplasia prostática benigna e câncer de próstata.

Sistema Respiratório

Pulmão: ocorre diminuição no tamanho e volume, devido a diminuição nos espaços intervertebrais e calcificação das articulações. Aumenta em 30\% o esforço para respirar. Diafragma: torna-se mais achatado, portanto a contração muscular torna-se menos eficiente. Músculos acessórios: diminuem de tamanho e força, diminuindo assim a capacidade de reserva inspiratória. Alvéolos: ductos alveolares dilatam-se e ocorre perda da elasticidade. Respostas normais a hipóxia e hipercarbia são reduzidas nas pessoas idosas.

Sistema cardiovascular

O coração de um idoso bombeia tão bem quanto o coração de um jovem. A função cardíaca parece que não decai com a idade. Entretanto, ocorre um estreitamento na parede cardíaca. A taxa cardíaca é mais baixa nos idosos. Ocorre diminuição na elasticidade da aorta e artérias. A massa ventricular esquerda tende a aumentar. Resposta a catecolaminas tende a diminuir. Resistência vascular periférica tende a aumentar. Incidência de doenças cardiovasculares (DCV) aumenta com a idade (como arritmias e cardiopatia isquêmica). A relativa imunidade da mulher a eventos cardiovasculares devido aos efeitos protetores do estrogrênio é perdida após a menopausa, 
tornando-a mais suscetível a DCV na pós-menopausa. Pressão sistólica tende a aumentar (25\% dos homens e 40\% das mulheres com idade acima de 75 anos têm hipertensão arterial sistêmica, usualmente hipertensão sistólica isolada).

Sistema rena

Função renal diminui após os 30 anos de idade numa taxa de $1 \%$ ao ano. Ocorre perda funcional dos néfrons. Os rins diminuem seu tamanho em cerca de $30 \%$. Estas modificações tendem ao aparecimento da hipercalemia (aumento do potássio plasmático). A filtração glomerular diminui. O fluxo sangüíneo renal diminui aumentando a suscetibilidade a isquemia renal.

Sistema endócrino

Ocorrem mudanças relacionadas com as diferentes glândulas corporais. Descobriu-se que a secreção de muitos hormônios diminui com a idade, como insulina, testosterona e aldosterona. Estudos como o de Framingham indicam que o hipotireoidismo pode estar presente em $6 \%$ das mulheres e $2 \%$ dos homens com idade superior aos 60 anos. No caso da insulina, a sua diminuição pode levar a diabete melito. Cerca de $25 \%$ da produção de cortisol é reduzida no idoso. Ocorre diminuição da síntese de vitamina D na pele e diminuição da absorção da mesma pelos intestinos (favorecendo o aparecimento de osteoporose).

Sistema imunológico

Este sistema protege o corpo da invasão de microorganismos e partículas estranhas ao nosso corpo. Como começa a ocorrer um mal funcionamento com o envelhecimento: 1) o organismo não reconhece com tanta eficiência os antígenos (aumentando a suscetibilidade a doenças infecciosas); 2) este sistema aumenta tanto a sua vigilância que passa a atacar as células do próprio organismo (aumentando a prevalência de doenças auto-imunes). 


\section{Sistema esquelético}

Ocorre perda do tecido ósseo em todas as pessoas, só que o índice varia individualmente. Os homens perdem cerca de $17 \%$ de sua massa óssea e as mulheres, $30 \%$. Mulheres pós-menopáusica tendem a desenvolver osteopenia e osteoporose.

\section{Sistema nervoso central}

Ocorre diminuição do peso do cérebro, redução das circunvoluções e morte de neurônios (embora não ocorra morte em todas as regiões do cérebro). Doenças associadas ao envelhecimento do cérebro: demências e doença de Parkinson.

\section{Mudanças cognitivas}

A memória de curto prazo (recente ou de fixação) e o raciocínio diminuem, já a memória remota (de evocação) permanece inalterada. A capacidade de aprendizagem verbal diminui após os 70 anos. O declínio cognitivo associado ao envelhecimento é considerado um processo normal, contrapondo-se ao mal de Alzheimer (tipo de demência).

Como tecer comentários sobre cada um dos aspectos compilados na síntese acima seria uma tarefa exaustiva e maior do que a que se propõe este artigo, comentaremos algumas situações mais gerais, a título de exemplificarmos, como podemos manejar estas informações para diminuir os efeitos associados às mesmas, ou até mesmo desacelerar (não evitar) o seu aparecimento.

O nosso corpo é composto basicamente por quatro grandes componentes: água, tecidos, gordura, e ossos. Aos 25-30 anos, proporcionalmente, nós possuímos mais tecidos, mais massa óssea e mais água intra-celular. Ao longo dos próximos trinta a quarenta anos, tendemos a adquirir mais gordura, e a perder os demais componentes. Somente a água extra-celular é que tende a se manter constante, independente da idade. Qual a importância de sabermos tal 
informação? Se estas modificações ocorrem, elas acabam nos predispondo a mudanças fisiológicas que podem interferir na nossa vida cotidiana e até mesmo estar relacionadas com a evolução de doenças (morbidades). Vejamos um exemplo: a perda de água intra-celular, torna a pessoa idosa mais propensa a se desidratar. Portanto, é fundamental que, a medida em que vamos envelhecendo, adquiramos o hábito de beber líquidos (principalmente água) mesmo que não estejamos com sede. Assim, ideal seria que as pessoas ingerissem, pelo menos, dois litros diários de água.

Adicionalmente, modificações no conteúdo hídrico podem significar uma modificação na absorção, degradação e excreção de medicamentos. Se a medicação é do tipo lipossolúvel (diluí-se na gordura), ela tende a concentrarse em maior quantidade no tecido adiposo do que no plasma. Com isto, existe uma tendência de que o fármaco fique depositado nos tecidos e sua liberação seja mais lenta. Como conseqüência, o efeito do fármaco age por mais tempo num idoso do que em um adulto jovem. Um exemplo de fármaco lipossolúvel, são os chamados benzodiazepínicos, conhecidos como "calmantes". Já os fármacos hidrossolúveis, possuem uma dinâmica inversa no idoso, permanecendo mais concentrados no plasma sangüíneo e, assim, agindo mais intensamente nos órgãos ou sistemas corporais alvo. Um exemplo deste tipo de medicamento são os diuréticos. Portanto evidenciamos, cientificamente, que a ação dos fármacos pode ser diferenciada conforme a idade da pessoa. Se isto é uma verdade, a indústria farmacêutica deve, nos próximos anos, mobilizar recursos a fim de adequar suas bulas `a prescrição diferenciada das doses dos fármacos para idosos. Ou seja, como já acontece com as crianças, as bulas deverão conter informações sobre dosagens recomendadas para idosos. Além disto, todo um segmento da indústria farmacêutica deve ser desenvolvido no próximo período, inclusive, para adequar o melhor tipo de apresentação dos fármacos para os idosos. Isto porque, com o acúmulo de outras modificações morfo-fisiológicas, muitas vezes o idoso corre o risco de exposição a super ou sub-dosagens medicamentosas. Ambos os casos não são situações benéficas e necessitam ser corrigidos sob "a luz das evidências científicas a respeito do envelhecimento biológico".

Já a diminuição da quantidade de tecidos, significa um decréscimo na 
massa magra corporal (massa muscular). Esta condição pode levar à diminuição do vigor e capacidade física aumentando, inclusive, o risco de quedas. Aqui, mais do que nunca, a atividade física regular passa a ser um elemento chave na prevenção da diminuição da massa muscular. $\mathrm{O}$ ideal é que adultos jovens façam exercícios regulares e aeróbicos de pelo menos 30 minutos três vezes por semana. Entendemos por exercícios aeróbicos, aqueles que geram aceleração das freqüências cardíaca e respiratória. Dado que, como foi comentado antes, não envelhecemos de modo uniforme, aqui, mais do que nunca, é necessária uma avaliação médica e de um educador físico para ajustarmos o quanto e o que devemos fazer de exercícios semanais, principalmente se a pessoa tiver mais de 60 anos de idade.

Adicionalmente, trabalhos recentes sobre nutrição e envelhecimento mostram que, devido a maior facilidade de perda muscular na velhice, existe uma necessidade de maior ingestão de proteínas diárias pelos idosos do que pelos adultos mais jovens. Enquanto recomenda-se que adultos comam cerca de 0.8 gramas de proteína por quilo de peso corporal por dia $(\mathrm{g} / \mathrm{Kg} / \mathrm{dia})$, muitos trabalhos já sugerem que idosos devem ingerir de 1.0 a $1.25 \mathrm{~g}$ de proteína/Kg/ dia, conforme suas atividades. Portanto, é fundamental na dieta do idoso, ovos, leite e carne.

Para diminuição do risco de quedas, os idosos devem eleger sapatos leves, confortáveis, com solado anti-derrapante e com saltos não muito altos para andar distâncias mais longas, ou até mesmo para o trabalho cotidiano. Além disto, uma situação patológica muitas vezes pode se instalar no nosso corpo (principalmente no sexo feminino): a osteoporose. Esta condição, apesar de ser comum em mulheres pós-menopaúsicas, não é normal e, sim, patológica. Assim, cuidar onde caminhamos e o que estamos fazendo, ao invés de nos encerrarmos nas preocupações e outras distrações que a nossa mente trabalha quando realizamos atividades de repetição, como caminhar por exemplo, é um comportamento preventivo importante. Neste sentido, os estudos demonstram que, com o passar da idade, precisamos cada vez mais nos relacionarmos com o nosso meio de forma a diminuir nossos riscos de acidentes.

Um outro conjunto de modificações morfológicas que acabam afetando o nosso organismo ao longo da vida, é a mudança do peso dos órgãos, 
modificações anatômicas e modificações nos sistemas corporais, que também podem ser manejadas com a perspectiva de "comprimirmos o período de morbidades que ocorrem na velhice". Ou seja, diminuirmos a possibilidade e o período de tempo que potencialmente ficaríamos doentes.

Se tomarmos o conjunto destas informações, podemos perceber o quanto é difícil manejarmos concretamente o nosso organismo para desacelararmos o processo de envelhecimento. Isto porque, sempre existirá uma grande variação entre os sistemas corporais de uma mesma pessoa, e desta pessoa em relação a outras pessoas. Portanto, fórmulas "anti-envelhecimento" são uma falácia oportunista de quem quer tirar proveito de uma situação biológica ou tirar proveito de quem nega tão violentamente sua condição humana, e portanto, sua condição de pessoa que irá potencialmente envelhecer (gerontofobia) que se predispõe em acreditar que fontes da juventude existem.

O mais fácil mesmo, é manejarmos o nosso envelhecimento, para que a curva do declínio biológico seja o mais desacelerada possível, e as mudanças associadas a idade sejam acumuladas tão lentamente que permitam, o indivíduo se adaptar a elas e conviver com elas de modo a garantir sua qualidade de vida. É importante salientarmos que não estamos sugerindo uma ação comportamental que poderia ser chamada de "envelhecimento radical". Ou seja, a idéia que devamos viver do modo mais asséptico possível, aceitando heroicamente cada ruga que aparece o rosto. Ao contrário, aceitar o processo não significa não manejar o processo. Assim, sem exageros, cada pessoa deve buscar o que mais lhe faz bem. Se isto inclui uma correção plástica, ou outros estratagemas de embelazamento, por que não? É uma questão muito pessoal. Ao nosso ver, manutenção das condições psicológicas e emocionais da pessoa devem ser preservadas. Portanto, pessoas que se percebam "vaidosas" (percepção esta que está presente muito precocemente na vida dos indíviduos) devem preservar sua percepção e suas atitudes comportamentais relacionadas. Assim como aceitamos hoje que velhice não é doença, devemos passar a aceitar que em cada momento de nossas vidas podemos ser e nos sentir belos, amados e produtivos.

Como o nosso corpo é complexo e cheio de "subdivisões", é impossível tratarmos neste artigo sobre as modificações biológicas causadas em cada órgão 
e sistema corporal, e como podemos manejá-las.

No entanto, o processo de troca de paradigma, onde envelhecer seja considerado um processo normal, como é quando trocamos os nossos dentes temporários pelos permanentes, é um desafio relacionado, principalmente, com os profissionais da saúde e das ciências humanas. No caso, seria interessante que médicos das mais diversas especialidades, começassem a implementar uma visão "geriátrica e gerontológica" nos seus consultórios, no sentido de atender com maior eficiência seus pacientes idosos, a partir da visão de que o momento biológico em que o mesmo se encontra difere daquele observado no adulto jovem, que costuma ser a referência clínica da maioria das especialidades.

Além do profissional da saúde, a visão "geriátrica e gerontológica" também pode ser positiva para o resto da população em geral. Ou seja, consideramos importante e necessário que as pessoas tenham cada vez mais discernimento de quais modificações são consideradas próprias e esperadas no envelhecimento e quais são as que ultrapassam o limite da normalidade, passando a ser consideradas associadas a doenças. Para tanto, é crucial sabermos com mais detalhe aspectos da biologia do envelhecimento humano e estimularmos tanto a disseminação do conhecimento acumulado sobre o tema, quanto pesquisas biogerontológicas complementares.

\section{Conclusão}

Para finalizar nossas reflexões sobre a biogerontologia e sua conexão com o "mundo social”, não poderíamos deixar de comentar que acreditamos que o processo de envelhecimento como um todo, bem como o seu manejo, sempre passa pelo filtro "da cultura". Segundo o biogerontológo Robert Arking "Nós reagimos ao nosso envelhecimento conforme a nossa cultura nos ensina" (Arking, 1998), portanto, só mudaremos o paradigma da marginalização e da exclusão do elemento idoso em nossa sociedade, se agirmos de modo conseqüente na "cultura do futuro adulto". Para tanto, o principal instrumento para atingirmos tal objetivo é a educação dos grupos etários juvenis em nossa população. Educação que leve a ruptura da ignorância sobre o processo biológico do envelhecimento. Processo que, até os dias de hoje, foi silenciado nos bancos escolares de todos os níveis de ensino, incluindo aqui muitos cursos 
em nível graduação da área biomédica. Educação que leve ao manejo do conhecimento sobre o que significa a velhice e como devemos nos preparar para envelhecer. Educação que nos permita resgatar a nossa história, através da "visão multiprismática" que somente a experiência humana pode dar, através do resgate da memória dos idosos.

Isto porque, se para a biologia nada faz sentido a não ser sob a luz da evolução, para a biogerontologia humana nada faz sentido a não ser sob a luz dos aspectos psicossociais que permeiam a vida dos indivíduos e da nossa sociedade. Para tanto, devemos resgatar a unidade e a interação entre as ciências biomédicas-ciências humanas, e nos parece que a biogerontologia

humana poderá servir como uma ponte, visto que, em essência, este ramo das ciências biológicas é

fortemente generalista, integrador e interativo.

\section{Agradecimentos}

Ao professor doutor Johannes Doll, pela sugestão e convite para a produção deste artigo e pela revisão inicial do texto, aos pesquisadores do Programa Genesis do Laboratório de Bioquímica e Genética Molecular-IGG/ PUCRS, às agências governamentais de fomento CNPq, CAPES e FAPERGS.

\section{Referências}

1 ARKING R. Human Aging. In: ARKING, R. Biology of aging. $2^{\text {a }}$ ed. Sunderland: Sinauer, 1998, p.153-250.

2 BELLAMY D. The Subject of Gerontology. In: BELLAMY D. Ageing: a biomedical perspective. Chichester: Wiley, 1995, p.1-35,.

3 BONNER J. A Evolução da Cultura nos Animais. São Paulo: Cultrix, 1996,

$365 \mathrm{p}$.

4 HAYFLICK L. Como e Porque Envelhecemos. São Paulo: Campus, 1996, $366 \mathrm{p}$.

5 MARTIN GM. Genes that Modulate Longevity and Senescence. In: ROBINE J.-M., et al. The Paradoxes of Longevity. Heidelberg: Springer, 1999, p.11-21. 6 VELLAS B.; ALBAREDE, J.L.; GARRY, P.J. Longitudinal Interdisciplinary Study on Aging. 2a ed. Paris: Serdi Publisher, 1997, 188p. 